\title{
Aspiração de querosene em engolidora de fogo*
}

\author{
FABRício Piccoli ForTunA ${ }^{1}$, AdAlBeRTO SPERB RUBiN ${ }^{2}$
}

\section{COMENTÁRIOS}

A aspiração de compostos formados por hidrocarbonetos ocorre mais freqüentemente em crianças menores, secundária à ingestão de produtos caseiros que contenham tais elementos. Sua ocorrência em adultos é infreqüente, principalmente relacionada a acidentes ocupacionais ${ }^{(1)}$.

Mulher de 20 anos de idade, engolidora de fogo em um circo em temporada na região, apresentou-se na emergência da Santa Casa de Misericórdia de Porto Alegre (ISCMPA) quatro dias após ter aspirado querosene durante uma apresentação. Referia febre de até $38,5^{\circ} \mathrm{C}$, tosse seca, dor torácica ventilatório-dependente, mal localizada no hemitórax direito, e dispnéia rapidamente progressiva ao nível de repouso, que se iniciaram aproximadamente 12 horas decorrentes do acidente. Ao exame físico, encontrava-se em bom estado geral, sem alteração no estado mental. A sua temperatura axilar era de $36,8^{\circ} \mathrm{C}$ e estava normotensa. A oximetria digital indicava saturação da hemoglobina de $95 \%$ em ar ambiente. A paciente estava taquipnéica em repouso (24mrpm), e a sua ausculta pulmonar era normal. A Figura 1 ilustra a radiografia frontal de tórax realizado nesse momento. Seu hemograma revelou hemoglobina de 10,8g/dL, 10.022 leucócitos com $70 \%$ de neutrófilos, sem formas jovens. As três hemoculturas bem como o exame de escarro demonstraram ausência de bactérias. O restante da avaliação laboratorial foi normal. A paciente foi submetida a uma tomografia computadorizada de tórax (Figura 2), que demonstrou focos de consolidação e atelectasia no lobo médio, especialmente no segmento lateral, sem alteração brônquica.

\footnotetext{
* Trabalho realizado no Pavilhão Pereira Filho - ISCMPA, Fundação Faculdade Federal de Ciências Médicas de Porto Alegre (FFFCMPA), Porto Alegre, RS.

1. Médico Residente em Pneumologia.

2. Doutor em Pneumologia. Médico Pneumologista do ISCMPA. Professor Substituto de Medicina Interna da FFFCMPA.

Endereço para correspondência - Adalberto Sperb Rubin, Rua Almirante Abreu, 246/402 - 90420-010 - Porto Alegre, RS. E-mail: arubin@terra.com.br
}

Recebido para publicação em 3/9/01. Aprovado, após revisão, em 8/4/02.
A paciente evoluiu satisfatoriamente, não apresentando febre ou qualquer sintoma respiratório. No quarto dia de hospitalização, completou 24 horas de observação com freqüência respiratória normal, sem sintomas, recebendo, então, alta hospitalar.

Diagnóstico: pneumonite química provocada em adulto pela aspiração direta de querosene.

O conhecimento a respeito da intoxicação por querosene e outros hidrocarbonetos deriva fundamentalmente de séries de casos na população pediátrica e estudos experimentais em animais. Poucos trabalhos relatam tais acidentes em adultos, $e$ isso provavelmente reflete o fato de que o pulmão na criança tolera pior a quantidade freqüentemente aspirada para as vias aéreas durante ingestões acidentais, em média, algumas dezenas de mililitros ${ }^{(2-4)}$.

Estudos em animais demonstraram que o querosene é inicialmente deglutido em sua maior parte, sendo que o volume total aspirado é a soma do que inicialmente adentra a traquéia e daquele que o faz após a regurgitação, muito freqüente nesses casos. Daí a recomendação de evitar o vômito induzido ou a lavagem gástrica em intoxicações por hidrocarbonetos, que sabidamente aumentam o risco de aspiração, da qual decorrem a maior morbidade e mortalidade.

Na maioria dos casos, o paciente é visto pelo médico dentro de uma a duas hora após o acidente. A história quase que invariavelmente fornece o diagnóstico, com início imediato de sufocamento e tosse, geralmente associados a franco desconforto respiratório. Esses sintomas indicam envolvimento traqueobrônquico precoce, sugerindo, portanto, aspiração. Seguem-se desconforto gástrico, geralmente com vômito, o que, como assinalado anteriormente, favorece o risco de nova aspiração. Após, dependendo da quantidade ingerida, o quadro clínico pode ser dominado por complicações da toxicidade no sistema nervoso central, como letargia, convulsões e coma. O paciente pode também apresentar o hálito sugestivo de contato com combustíveis. Ademais, ao exame físico, pouco mais do que taquipnéia pode ser observada, e a ausculta pulmonar comumente é normal. A radiografia de tórax, entretanto, revela pneumonite peribrônquica em um número significativo de casos, a partir dos primeiros 30 minutos. A maioria dos pacientes apresenta altera- 


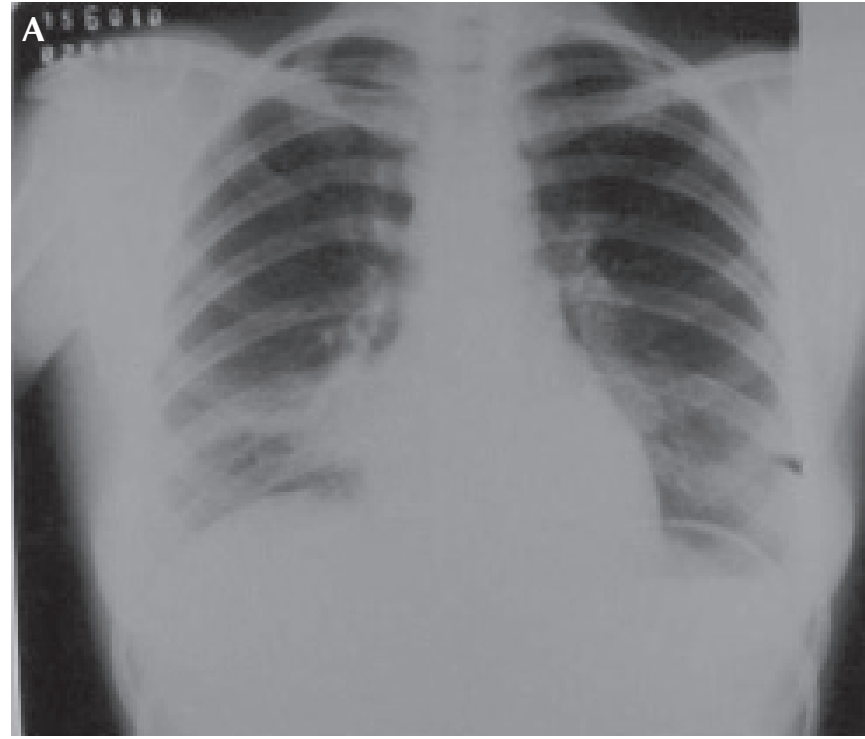

\section{B}

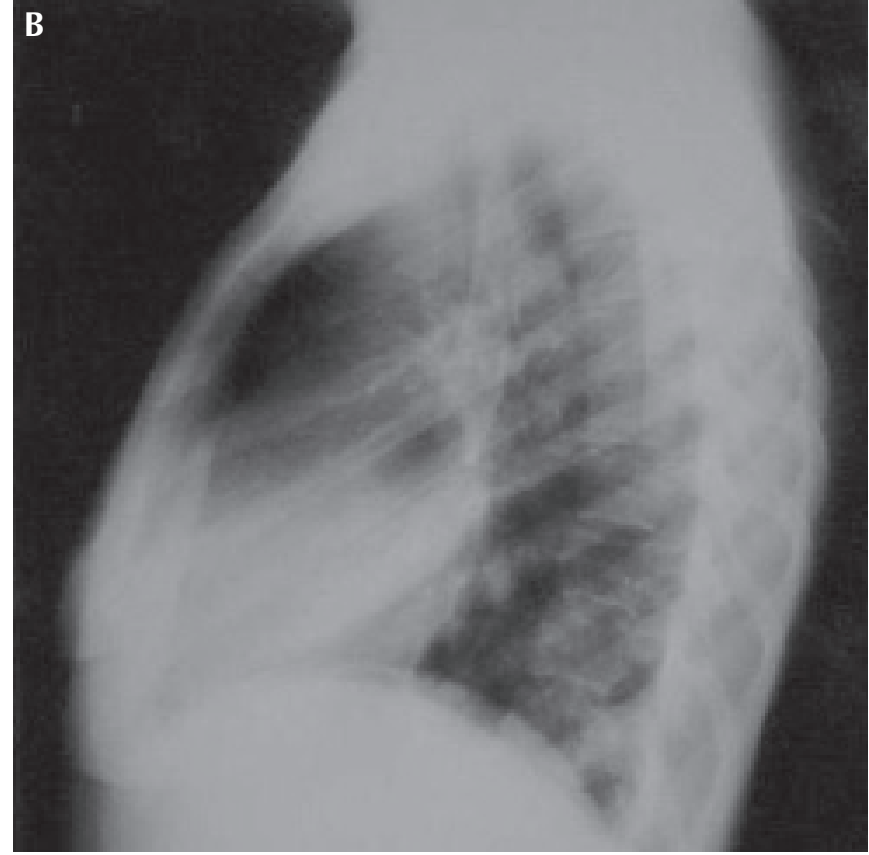

Figura 1 - Radiografia convencional frontal e perfil de tórax

ções radiológicas dentro de 12 horas do acidente, mesmo com a primeira radiografia normal. Num estudo de Daeschner et al. ${ }^{(2)}$ com 149 crianças, febre foi achado comum (76\%) e, dos 65\% que apresentaram alterações radiológicas, $98 \%$ o fizeram até as primeiras 12 horas. Os achados radiológicos iniciais podem desaparecer em 24 a 36 horas, ou progredir para densidades confluentes, representando consolidações e/ou atelectasia, usualmente associadas a enfisema compensatório circunjacente. A mortalidade referida em crianças varia de 1,3 a $10 \%$.

A maioria dos pacientes recupera-se em alguns dias e, embora corticosteróides tenham sido utilizados com fre-
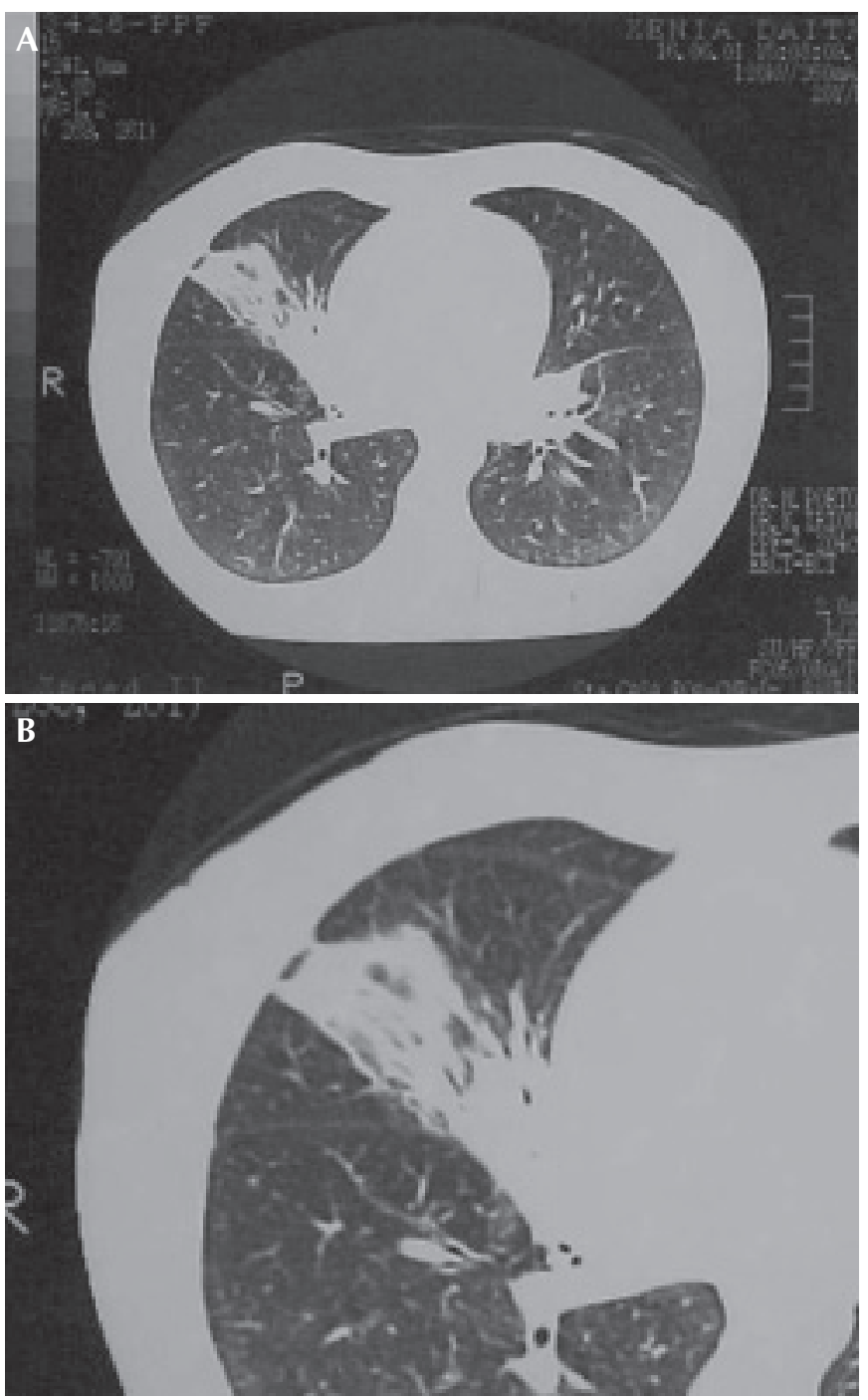

Figura 2 - Tomografia computadorizada de tórax

qüência no passado, não há evidência conclusiva para recomendar seu uso(5). Sintomas nas primeiras 48 a 72 horas são atribuíveis à pneumonite química; antibióticos devem ser utilizados na persistência de sintomas, principalmente febre, além desse período, pela possibilidade de uma infecção bacteriana sobreposta à pneumonite ${ }^{(6)}$. Oxigênio e suporte ventilatório devem ser utilizados conforme a necessidade.

A paciente em estudo procurou atendimento médico tardiamente em comparação com a maioria dos casos descritos, sendo que em adultos os sintomas podem surgir até 24 a 48 horas após a aspiração do produto. Terapêutica empírica com antimicrobianos ativos contra bactérias gram-negativas entéricas é justificada somente em casos de suspeita de aspiração concomitante do conteúdo gástrico. As anormalidades radiológicas encontradas 
inicialmente e mais tardiamente, registradas por tomografia computadorizada, são as mesmas referidas na literatura, ou sejam, a progressão de tênue infiltração ao longo de feixes broncovasculares para consolidação e atelectasia do segmento comprometido.

Em resumo, a pneumonite química induzida por querosene é relativamente incomum em adultos, sendo o seu

\section{REFERÊNCIAS}

1. Ewert R, Kern F, Mutze S, Witt CH. Aspiration of petroleum by a "fireeater". Pneumologie 1995;49:388-90.

2. Daeschner WC, Blattner JR, Collins VP. Hydrocarbon pneumonitis. Pediatr Clin North Am 1957;4:243.

3. Bye MR, Mellins RB. Lung injury from hydrocarbon aspiration and smoke inhalation. In: Chernick V, Boat T. Kendig's disorders of the respiratory tract in children. $6^{\text {th }}$ ed. Philadelphia: WB Saunders, 1998. diagnóstico obtido pela história clínica. Uma anamnese adequada acompanhada de exame radiológico quando do início dos sintomas traz subsídios importantes para o diagnóstico da aspiração por querosene e contribui de maneira significativa para o diagnóstico diferencial desta entidade em relação a processos pneumônicos por agentes infecciosos.

4. Segev D, Szold O, Fireman E, Kluger Y, Sorkine P. Kerosene-induced severe acute respiratory failure in near drowning: reports on four cases and review of the literature. Crit Care Med 1999;27:1437.

5. Albert WC, Inkley SR. The efficacy of steroid therapy in the treatment of experimental kerosene pneumonitis. Am Rev Respir Dis 1968;98: 888.

6. Marik PE. Aspiration pneumonitis and aspiration pneumonia. N Engl J Med 2001;344:665. 